\title{
En torno a la "audiovisualización" de la comunicación publicitaria
}

\section{Around the "audiovisualisation"of advertising communication}

\author{
Dr. José Antonio MUÑIZ VELÁZQUEZ \\ Universidad Loyola Andalucía (España) \\ jamuniz@uloyola.es
}

Recibido: 30 de agosto 2013

Aceptado y Publicado: 4 de octubre de 2013

\begin{abstract}
Resumen
Parece que el futuro de la publicidad pasa irremediablemente por un proceso continuo de "audiovisualización", esto es, de la transformación de todo tipo de formatos, canales y soportes en una modalidad audiovisual de comunicación publicitaria. Así está siendo en ámbitos tan a priori distintos como Internet, la publicidad exterior, la publicidad en el móvil y otros dispositivos, etc. Al mismo tiempo, y paralelamente a ello, también parece predominante el fenómeno de la hibridación entre distintos canales y modalidades, la interactividad creciente, lo que dará pie a la "gamificación", por un lado, la transmedialidad, por otro, y la generación de contenidos publicitarios y de marca también por parte de los receptores, consumidors y/o usuarios, todo lo cual da pie a pensar que estamos ante un cambio de paradigma de la comunicación publicitaria en muchos de sus aspectos, donde el poder de la comunicación se reparte de manera mucho más equilibrada entre emisor y receptor, marca y consumidores, donde la frontera entre unos y otros queda diluida y que condicionará sobremanera la construcción de los mensajes publicitarios.
\end{abstract}

\section{Abstract}

It seems that the future of advertising is inevitably a continuous process of "audiovisualisation", ie the transformation of all formats, channels and supports a visual form of advertising communication. So being a priori in fields as diverse as Internet, outdoor advertising, advertising on mobile and other devices, etc. At the same time, parallel to it, also appears predominantly the phenomenon of hybridization between different channels and modalities, increased interactivity, on one hand giving rise to a " gamefication ", on the other 
hand the transmediality, and also the generation advertising content and brand from the receivers, consumidors and / or users, all of which leads to think that this is a paradigm shift of advertising communication in many aspects, where the power of communication distributed in a much more balanced between sender and receiver, brand and consumers, where the border between them is greatly diluted and will condition the construction of advertising messages.

Palabras Clave: Publicidad audiovisual; publicidad digital; advergaming; publicidad móvil; comunicación audiovisual.

Key Words: Audiovisual advertising, digital advertising, advergaming, mobile advertising, visual communication.

\section{Introducción}

Antes de empezar a hablar del futuro de la comunicación publicitaria en general, y de la publicidad audiovisual y televisiva en particular, habría que preguntarse por el significado de dichas palabras, como advierten Lowrey et al. (2005: 114): "What do we mean by 'the future", by 'television', and by 'advertising'?" En cuanto a future, como premisa fundamental y antes de seguir hablando de advertising y de television, es cierto que habría que ser prudente en las predicciones, habida cuenta de la vertiginosidad de los cambios y avances tecnológicos, mediáticos, sociales, y de toda índole que se vienen sucediendo. Por ello, nunca parecerá prudente sobrepasar el plazo de vigencia que para toda predicción otorga dicho autor, de unos 10 a 15 años, cosa que ya parece excesiva en un ámbito como el de la publicidad en general, y de la audiovisual en particular, y máxime si tenemos en cuenta el escenario digital que circunda a todo ello.

Partiendo de esta condición, al mirar hacia el futuro, en concreto al que le puede aguardar a la publicidad audiovisual, lo que llama la atención, por encima de otras consideraciones, es la conquista que de multitud de medios está llevando a cabo. La publicidad audiovisual ya no se limita a estar presente en el cine y en la televisión, sus dos medios tradicionales. Poco a poco va conquistando terrenos, canales y dispositivos que hasta ahora no permitían una comunicación audiovisual y que gracias, entre otras cosas, al empuje de la industria publicitaria sí lo permiten en la actualidad. No por ello el cine y la televisión dejarán de ser escenarios preminentes de publicidad audiovisual, si bien teniéndose que adaptar a un sistema y unas prestaciones en continuo cambio e innovación. Cierto es que en el caso del cine, por su propia naturaleza, no ha modulado en exceso sus condicionantes y potencialidades de cara a acoger publicidad. Dejando aparte las fórmulas más o menos 
novedosas de hibridación entre contenido y publicidad, entre película y anuncio, lo cierto es que a día de hoy el cine aún aguarda la aparición de fórmulas novedosas y originales que posibiliten un aumento en la creatividad y, por tanto, en la eficacia publicitaria ${ }^{1}$. La que sí ha sufrido grandes y numerosos cambios es, en cambio, la televisión de los últimos años.

\section{Antecedentes}

\subsection{La publicidad audiovisual: de la vieja a la nueva televisión}

Hace ya varios años que el sistema publicitario audiovisual ha ido buscando nuevos formatos con los que sortear el hastío ante los modos tradicionales de hacer publicidad en televisión, y que provocó fenómenos como el zapping, el flipping (recorrido a la deriva por los diferentes canales, oteando la programación), el grazzing (simultanear dos programas), o el zipping (ver un programa de televisión grabado previamente y pasando rápidamente los spots). Hastío también ante tal saturación publicitaria y mediática, no sólo en España sino en todos los países de nivel de desarrollo semejante de la sociedad de consumo. Y ello parece debido a varios factores: una primera lucha llevó a sacar la publicidad de sus rincones habituales e invadir territorios nuevos de la programación, buscando fórmulas publicitarias nuevas, que pronto se irían viendo igualmente agotadas; a la multitud de anunciantes que salen por pantalla se unen también las propias cadenas, que ante la guerra de descuentos entre ellas necesitan conseguir audiencia, vendiéndose a través de los bloques autopromocionales como un producto más, y conseguir así un mejor share con el que salir al mercado (García Uceda, 1995).

Además de lo dicho, el perfil de la televisión en un futuro cercano vendrá previsiblemente marcado por el desarrollo de varios factores. En primer lugar, por la televisión local, cada vez más numerosa y de mayor calidad técnica y profesional, aunque hoy por hoy su consumo sigue siendo minoritario, amén de presentar problemas de audimetría. En segundo lugar, la llegada de la televisión digital ha dado lugar a otro tipo de canales: sectoriales, de servicios, tematizados, entre otros, lo que a medio y largo plazo llevará a la televisión como medio publicitario por derroteros diferentes. Los usos y formatos publicitarios en esos nuevos soportes también habrán de ser diferentes, en pro, principalmente, de la ya mencionada interactividad y coprotagonismo de los receptores. Como decía García Uceda (1995: 319) "la televisión evoluciona hacia un medio interactivo con amplias posibilidades en el campo educativo, informativo, de ocio y evidentemente, publicitario". Ello se completa con una

\footnotetext{
${ }^{1}$ Habrá que ver, a este respecto, lo que puede suponer en términos publicitarios la futura digitalización online de la distribución de películas.
} 
desmasificación del medio, algo que ya comenzara en los años 90 (Anaut, 1990), y que despega irreversiblemente con el cambio de siglo.

Por ahí irá precisamente el tercer factor determinante del futuro de la publicidad en televisión. Esto es, la progresiva conquista de la ya mencionada interactividad, el rompimiento de la unilateralidad del medio hacia terrenos más allá de esos primeros experimentos de "bilateralidad imperfecta" (Sanabria Martín, 1994: 33): llamadas telefónicas, presencia de público, conexiones con lugares donde se encuentran algunos destinatarios, etc. Interactividad en televisión engloba también la telecompra especializada, la telebanca, concursos, juegos y loterías, viajes, reservas... aunque cada vez está más cerca un verdadero diálogo simultáneo entre el emisor y el telespectador, lo que publicitariamente hablando, supondrá un cambio en las maneras de hacer, y el destierro definitivo de ese espectador pasivo que denunciara en su momento Saborit (1988). En ese sentido, el anunciante podrá y deberá pasar de invasor a invitado, acorde con el nuevo paradigma de una publicidad fundamentada sobre estrategias "pull", que buscan atraer al receptor hacia el mensaje, en lugar de estrategias "push", mensajes que de alguna manera empujan al público (Martí Parreño, 2005). Ambos conceptos toman aún mayor cuerpo a la hora de hablar de la publicidad en otros medios no convencionales, cosa que se hará con detenimiento más adelante.

Paralelamente a ello, otro factor de especial importancia es lo que algunos han dado en calificar como "Televisión Social" (Chorianopoulos y Lekakos, 2008), para describir la eclosión de la presencia de las redes sociales digitales en las emisiones televisivas a través, y viceversa. Ese factor social de interacción continua entre el conjunto de receptores, hace que estos se acerquen a la figura de emisores casi al mismo nivel, según los casos, que el del emisor genuino, haciendo de la comunicación de masas también comunicación interpersonal. Al mismo tiempo, a lo señalado cabe añadirle otro elemento crecientemente determinante en el presente y futuro de la comunicación audiovisual, también publicitaria: la transmedialidad, que siguiendo los planteamientos de Jenkins (2003), puede venir definida como el desarrollo de una estructura convergente de una historia o relato que fluye en y a través de múltiples plataformas, medios y dispositivos (Gallego Aguilar, 2011). De esta suerte, como afirma Mu et al. (2013), son los usuarios los verdaderos editores de contenidos y de historias, los últimos hacedores de su propia "relatosfera".

Pase lo que pase con el desarrollo tanto comercial como tecnológico de la televisión, sea el camino que sea o el aparato a través del cual llegue a los consumidores, no se puede dejar de estar de acuerdo con O'Guinn, Allen y Semenik (1998: 432) cuando afirman que "algo parece seguro: la televisión seguirá creciendo como medio de diversión e información de las 
familias. Su comodidad, bajo coste y diversidad de programación la establecen como el medio ideal para los consumidores.”. En cualquier caso, parece razonable lo que apunta Bustamante Ramírez (1999), al afirmar que el papel de la publicidad en la nueva televisión digital se dividirá en cuatro caras: una publicidad más o menos tradicional en las cadenas generalistas; en segundo lugar, una publicidad especializada, patrocinios, etc., en las cadenas temáticas; tercero, patrocinios de producción y publicidad informativa imbricada en los canales de servicios; y en cuarto lugar, publicidad-información superespecializada con compra directa aprovechando la interactividad, lo que hará de la publicidad directa televisiva algo prominente. Todo ello implicará, avisa el autor, un cambio de estructuras de gestión, de relación entre los agentes, y también unas mayores exigencias creativas con las que sacarle el máximo partido a estas nuevas potencialidades.

Pero el futuro de la publicidad audiovisual, y el de la comunicación audiovisual en general, y el futuro de la televisión como se entendía hasta ahora, si bien siempre estarán hermanados de alguna manera, empiezan a bifurcarse en dos líneas diferentes, principalmente en el momento en el que entra en juego otro gran medio con posibilidad de ofrecer mensajes audiovisuales con unas prestaciones amplificadas: Internet. Ese brinco del televisor al ordenador que ya ha dado la publicidad audiovisual, ese salto de la "segunda pantalla" de la Historia (sería el cine la primera) a la "tercera", hará de la publicidad audiovisual algo mucho más versátil, independiente, multifuncional y por tanto, con mayor potencial para alcanzar la eficacia y la rentabilidad que siempre se le pidió.

\section{Discusión}

\subsection{La "audiovisualización" de la publicidad en Internet}

La televisión prescinde, por tanto, del televisor tal y como era conocido hasta ahora, aparato que si se hace caso a Pérez de Silva (2000), podría no quedarle demasiado tiempo de vigencia, al igual que a la forma actual de ver y hacer televisión. Umberto Eco ha dicho en alguna ocasión, quizás exagerando, que a la televisión de hoy día le quedan unos diez años de vida. Ya vaticinó en su momento Negroponte que "no existirá una industria de aparatos de televisión en el futuro, sino sólo fábricas de ordenadores, es decir, pantallas alimentadas con toneladas de memoria y un enorme poder de procesamiento" (1995: 66). Y continúa diciendo que la clave del futuro de la televisión es dejar de pensar en ella como tal, y concebirla en términos de bits. Más lejos llegó aún Dertouzos (1997), al predecir que el dispositivo que habría en el futuro sería una especie de "red corporal", como un tejido de módulos integrados 
(móvil, ordenador, TV, cámara...) alrededor del cuerpo, lo que engarza sobremanera con el enfoque de la transmedialidad mencionada.

Lo que sí puede ya verse es que, por ejemplo, la responsabilidad de seleccionar contenidos cada vez es menos de las cadenas y más de los receptores. Serán éstos los que crecientemente construyan programaciones a través de Internet, serán los usuarios los que decidan qué contenidos ver, amén de dónde quieran verlos, cuando quieran y como quieran. Esta e-TV, como la nombra dicho autor, o también conocida como IPTV (Internet Protocol TV) surge de la unión entre la televisión interactiva, incipiente en los televisores, como se veía más arriba, y el ordenador, con el más potente de sus armas, Internet. A todo ello habría que añadir, conviene no olvidar, la última de las pantallas llegadas a nuestras vidas, el móvil, que con su arsenal de prestaciones, con las apps como abanderadas, y su carácter social están por poner todo el panorama descrito patas arriba, como señalan, entre otros, Lochrie y Coulton (2012).

Pérez de Silva (2000) planteaba un debate en torno a si al final de esta imbricación entre televisión e Internet, dejando de momento de lado el tipo de dispositivo, saldría como resultado lo que él llama la Web TV o bien la TV web. La primera sería la integración definitiva del acceso a Internet en un nuevo concepto de televisor con la misma versatilidad que el PC. Eso sí, un televisor que llevaría anexa una serie de dispositivos que le otorguen mayores prestaciones de uso, como es el caso de los set-top box, descodificadores digitales que sirven para facturar canales de pago, interactuar con la programación, realizar órdenes de compra, transmitir datos, etc. Mientras que la TV web sería lo contrario, la sintonización de canales de televisión en el ordenador. Al final, el autor apostaba por un nuevo y único aparato, híbrido no sólo de televisor y ordenador (y de dispositivos móviles, bien teléfonos o tablets, cabe añadir hoy) sino también de vídeo, microcámara, teléfono, módem, y radio. La realidad y el avance de los hechos han hecho de este debate algo superado en buena medida. $Y$ en breve, tal vez hablar de IPTV y de TV a secas llegue a ser lo mismo, independientemente del dispositivo, fijo o móvil, por el que transite.

Alrededor de todo este nuevo planteamiento de la comunicación audiovisual a través de Internet, lejos queda ya aquel otro debate terminológico que equiparaba comunicación audiovisual con comunicación multimedia. A ésta la definió, entre otros, Garrand (2001), quien considera que para que un mensaje o un trabajo sea considerado multimedia había de reunir cuatro características básicas: combinar más de una modalidad sensorial, o "medio": vídeo, texto, audio, fotografía, etc.; estar mediado computacionalmente, usando el término computación extensamente. Como decía el autor, "no computer = no multimedia", pero entendiendo por computador todo dispositivo compuesto de un hardware y un software; 
asimismo, el mensaje debía ser alterable interactivamente. En ese sentido, define interactividad como la capacidad del usuario de alterar el mensaje que se pone en contacto con él; y por último, el mensaje tendrá que ser enlazable, es decir, que soporte el "linking”, un menú, o una narrativa hipertextual. Resumiendo, un mensaje multimedia implicaba "a combination of many media into a single work where media-altering interactivity and linking are made posible to the user via the computer" (Garrand, 2001: 4). En base a las características que la comunicación audiovisual parece estar adoptando, y que están siendo aquí señaladas, podría decirse que su equiparación completa con la comunicación multimedia ${ }^{2}$ es ya un hecho.

Al margen de esto, y más allá de lo terminológico, lo que resulta incuestionable es el conjunto de implicaciones que tiene todo ello para la publicidad audiovisual. Si son los usuarios los que deciden qué ver en tanto en cuanto televidentes, si está en sus manos la programación, a la publicidad no le queda más remedio que convertirse en algo programable, esto es, en programa, en contenido apetecible de ver por un usuario que ostenta más que nunca el poder de recibirla o no. La publicidad se verá obligada, lo primero, a seducir por sí misma para poderlo hacer luego en beneficio del producto o marca que publicita. Martí Parreño (1995) desgranaba una completa descripción de numerosas estrategias que ya se venían utilizando a tal respecto, como por ejemplo, el advertainment, donde la publicidad es entretenimiento antes que publicidad, o el advergaming, camuflada en juegos y videojuegos, donde se consigue la participación activa del receptor en la construcción del mensaje y sobre lo cual hablaremos más detalladamente más adelante.

Al principio de su expansión, Internet adaptó a la pantalla las formas de hacer publicidad de otros medios, principalmente impresos, añadiéndole cierto dinamismo, movimiento, y vistosidad, con color, sonido, etc. Pero los primeros avances del mercado publicitario en Internet no fueron por una línea recta, encontrándose con resultados no siempre satisfactorios, lo que provocó cierto escepticismo ante el nuevo medio. Hasta que no se aceptó que en Internet la publicidad debía funcionar de manera diferente, no como mera adaptación de lo impreso a los píxeles y sí más cercana a una nueva publicidad audiovisual, no ha empezado a encontrar su naturaleza diferencial y ventajosa. Por otro lado, en Internet son los usuarios los que deciden prácticamente todo, también a qué publicidad acercarse y a

\footnotetext{
${ }^{2}$ Lo multimedia podría acercarse, por otro lado, a lo hipermedia. En cambio, éste es más una extensión del concepto hipertexto, según Negroponte (1995). Se trata de un término que designa, desde que apareciera en 1965, aquella narrativa altamente interconectada, o lo que es lo mismo, información vinculada sobremanera a otras. El mismo Negroponte (1995), define multimedia como la combinación de sonido, imagen e información a través de "bits".
} 
qué publicidad obviar. Cada día parece quedar más claro que en esa enorme maraña informativa que supone la red, toda publicidad que no tenga la capacidad de atraer hacia sí misma será una publicidad inútil, algo que puede lograr en solitario o apoyándose de manera integrada en mensajes insertados en otros medios. Las vías para conseguir esa atracción son tan anchas, y constantemente ampliadas, por otro lado, por la imaginación de los propios usuarios metidos cada vez más a generadores de contenidos, que predecir modelos y formatos, cuando cada día surgen, se mezclan, y se superan varios nuevos, sería una temeridad. Pero en cualquier caso, parece que las puertas que se abran serán en mayor medida audiovisuales. Como afirmaban Moorey-Denham y Green "video ad formats are clearly more effective than other forms of online advertising at breaking through clutter and conveying messages." (2007: 45).

Por otro lado, estas mismas autoras señalan ciertas diferencias entre la televisión e Internet audiovisual. Lo primero, recomiendan, es no limitarse a llevar, sin más, el modelo televisivo al ordenador, aunque bien es cierto que tampoco se tiene por qué excluir por completo. La televisión se asocia a la relajación, al "lean back" (reclinación), como señalaba también León (1996), a momentos donde se busca entretenimiento y cierta información, pero desde una postura, aun física, relajada. Internet es, por regla general, todo lo contrario. Se trata también de un medio de búsqueda de información y de entretenimiento, pero de una manera activa e interactiva, de "lean forward" (aproximación), dicen las autoras. De tal suerte, la publicidad que no enganche de alguna manera con los intereses inmediatos del usuario, que no sepa aprovechar esa predisposición del mismo, prácticamente no existirá para sus ojos.

La creatividad sigue siendo considerada clave por estas autoras, pero en el sentido de que será responsable de que el usuario quiera volver a ver una segunda vez el vídeo publicitario, y poderlo así memorizar mejor. Aconsejan que sean vídeo cortos, más aún que los treinta segundos del spot televisivo, llegando a optar por los siete segundos como lo óptimo, lo que va a determinar que el contenido se centre en un solo mensaje, simple y directo. En tal caso, si se quiere construir lo que ellas llaman "brand stories", habrá que seguir alguna técnica, como la secuencialización o el "telescoping". La primera consiste en contar una historia de manera fragmentada en pequeñas micropiezas, insertadas por ejemplo en banners (Martí Parreño, 2005), que aun siendo parte de la historia global, tienen autonomía propia. La segunda, el "telescoping", es usar un fragmento corto de un vídeo que al final remite al sitio, la web de la marca, por ejemplo, donde se puede encontrar el vídeo completo.

En definitiva, por encima de las diferentes modalidades o presencias concretas que el vídeo publicitario pueda ir adoptando en la red, lo cierto es que su presencia va en aumento. A 
medida que va creciendo el ancho de banda ${ }^{3}$, el protagonismo del vídeo, de sonido e imágenes en movimiento que van mucho más allá de una mera animación de ilustraciones vectoriales, se ha ido haciendo indiscutible. Por tanto, lo que está resultando imparable es la creciente audiovisualización de Internet, y por ende, de la publicidad en la misma.

\subsection{Publicidad audiovisual como publicidad exterior, y viceversa}

Dejando el cine aparte, y antes de la gran revolución que ha supuesto Internet, ya la comunicación audiovisual había salido del televisor doméstico y de la intimidad del hogar. Antes de la web, también podría encontrarse comunicación audiovisual más allá del televisor, en ámbitos más o menos públicos, que iban desde locales de ocio hasta estadios, canchas deportivas, eventos culturales, y más recientemente, incluso fachadas de todo tipo de edificios. En ese sentido, varios han sido los dispositivos de emisión y proyección de información audiovisual que se vienen tanteando en esos nuevos ámbitos, los cuales incluso tocan espacios y soportes de publicidad exterior hasta ahora con un uso limitado a lo gráfico, donde el contenido que se exponía era impreso, bien en papel o vinilo, o sobre cualquier otro material. Ahí el mensaje audiovisual se está haciendo cada vez más presente. Hay ya marcas que incorporan en las marquesinas de autobús que contratan, o en las estructuras aisladas que soportan publicidad en las aceras, monitores por los que se reproducen de forma constante su spot, a la que además se le añaden ciertas posibilidades de interactividad y otras modalidades sensoriales.

Pero el gran avance, por el momento, vendrá de la mano de la tecnología $L E D$, acrónimo de Light Emiting Diode. Se trata de un diodo emisor de luz, un dispositivo semiconductor (que permite el paso de la corriente eléctrica en una única dirección) de unos cuatro centímetros de tamaño, que emite luz monocromática. Si bien es un dispositivo cuyo desarrollo cuenta ya con más de cuarenta años, cuando dio con él en 1962 N. Holonyak, un ingeniero de la General Electric, no ha sido hasta hace unos pocos años cuando se ha comenzado a explotar en todas sus posibilidades. Unas posibilidades que vienen dadas por las enormes ventajas técnicas que presenta: una gran fiabilidad ante posibles variaciones en el suministro eléctrico, amplios márgenes de tensión, mayor eficiencia energética, lo que puede suponer un ahorro de hasta el 80 y 90\%, su tamaño pequeño, lo cual otorga una enorme versatilidad. Tiene asimismo la capacidad para reproducir todos los colores, una enorme vida útil, mayor resistencia, y no presenta radiación, entre otras ventajas (Puig, 2005).

${ }^{3}$ Definido por Negroponte (1995: 31) como el "número de bits que se transmite por segundo a través de un canal determinado, ya sea hilo de cobre, fibra óptica o espectro de radio". 
Por tanto, no es de extrañar que este pequeño diodo constituya la base tecnológica de la nueva "gran imagen". Precisamente su pequeño tamaño hace que al unir la cantidad que se quiera de ellos dé lugar a una pantalla de la forma, tamaño y superficie que se desee, prácticamente sin limitación. Las aplicaciones de esto se llevan viendo hace tiempo, como se decía, en diferentes facetas. En publicidad hace ya unos años que Times Square u Oxford Circus muestran el aspecto de un gran portal de publicidad, repletas de LEDs que hacen de esos espacios urbanos toda una pantalla gigante de publicidad audiovisual. Las canchas y estadios deportivos hace tiempo que cambiaron la publicidad gráfica de las vallas a pie de campo por pantallas donde se anuncian los patrocinadores. Pronto podrá verse, de seguir esa tendencia, a otros formatos de publicidad exterior y urbana pasar de lo gráfico a lo audiovisual. Prácticamente cualquier soporte es susceptible de sufrir el cambio que le haga abandonar la imprenta por los LEDs. Gracias a esta tecnología, aunque no únicamente, la comunicación audiovisual, principalmente para uso publicitario, va conquistando espacios en las ciudades hasta entonces inverosímiles. La publicidad audiovisual, por tanto, se convierte también en publicidad exterior, y viceversa, suponiendo una integración exponencial de las ventajas de una y otra en un mismo mensaje.

Pero incluso cabe ir más lejos. Más allá del sistema de LEDs, la publicidad y la comunicación audiovisual, dentro de lo que podría seguir llamándose medio exterior, está ya capacitada para emanciparse de toda pantalla. El mensaje audiovisual, publicitario o no, es ya capaz de presentarse ante los receptores sin superficie plana y cuadrada alguna, sino en el aire mismo, tridimensionalmente. Para su consecución se presenta la tecnología del holograma, la cual está ya dando experiencias más que notables. Un holograma consiste en un sistema de rayos láser que es capaz de proyectar en el espacio un determinado contenido visual en tres dimensiones, y sin necesidad de ser soportado sobre una pantalla, como ya se ha dicho (Hewitt, 2004). Empezó su desarrollo reproduciendo imagen estática, pero hoy ya puede ser plenamente dinámica y en movimiento. Por tanto, audiovisual. Como afirman Smith y Chaffey (2005: 133), el ecosistema para el consumidor del futuro estará poblado en buena medida de hologramas, la mayoría de ellos publicitarios. Así, en el mismo momento en el que apenas ha llegado esa cuarta pantalla de la que también estamos hablando, los dispositivos móviles, irrumpe la no-pantalla como próximo paso inmediato e inminente por donde discurrirá, tanto en escenarios públicos como privados, en las calles y en las casas, la comunicación audiovisual, y con ella, la publicidad audiovisual.

\subsection{El advergaming como una nueva publicidad audiovisual emergente}

El videojuego constituye también una forma particular de comunicación audiovisual. Por un lado, es indudable que se trata de una conjunción de sonido e imágenes en movimiento, pero 
la representación visual de la realidad no es sobre fotografía, al menos por el momento, sino sobre animación tridimensional, desarrollada digitalmente. Por otro lado, la interactividad sería el rasgo definitorio por excelencia de la narración resultante de esta comunicación audiovisual. Como afirma García García, "los videojuegos no sólo son representaciones lúdicas, sino relatos en los que la participación de los jugadores es esencial para su desarrollo" (2006: 8). Por tanto, a la hora de hablar del videojuego como soporte audiovisual publicitario, lo será también de una publicidad puramente interactiva.

Pero al margen de ello, y aunque la industria de los videojuegos viene desde hace ya tiempo poniendo herramientas y canales a disposición de la comunicación publicitaria, lo cierto es que no es hasta los años recientes cuando esa presencia publicitaria en videojuegos comienza a denominarse "advergaming". Para ser exactos, este término vendría a recoger aquella publicidad que se presenta en forma de juegos electrónicos, fruto de la hibridación entre contenido de entretenimiento y contenido publicitario (Selva, 2009). Estos videojuegos publicitarios pueden presentar varias modalidades, como juegos de acción, de aventuras, de conducción, puzzles, juegos de role-playing, de simulación, deportivos, o de estrategia, entre otros (Hernández et al., 2005), si bien en todos ellos el mensaje publicitario se metamorfosea en contenido lúdico. Cierto es que no hay que esperar a la llegada del videojuego para ver tal fenómeno de imbricación entre el ámbito publicitario y el lúdico, puesto que en otro tipo de juegos y modalidades, como los de mesa, también habría aparecido publicidad mucho antes, si bien, de manera mucho más puntual y limitada, y sobre todo, sin las prestaciones que los juegos electrónicos ofrecen a la hora de vehicular mensajes, presencias de marcas y productos, y sobre todo, lo que viene en llamarse "experiencias de usuario", convirtiéndolas en "experiencia con la marca o el producto.

Hay que señalar que la presencia publicitaria en el videojuego no es siempre igual y uniforme en este sentido. A veces se limita a una mera presencia del anagrama de la marca, a modo de product placement televisivo o cinematográfico, con lo que la interactividad pasaría de puntillas, ya que la recepción del mensaje se produce de manera más pasiva. Pero otras veces, todo el desarrollo del juego electrónico gira en torno a la marca, el producto y/o el beneficio básico que de él se plantea, lo que constituiría un ejemplo de lo que algunos llaman "retórica procedimental", a través de la cual, el mensaje publicitario persuade gracias al papel plenamente activo del receptor, el cual participa de lleno en su configuración. Así, "the effect of brands placed in video games is much more intense because the user becomes part of the entertainment while interacting with the game." (Kaikati y Kaikati, 2004: 13)

Otra diferencia con respecto al product placement es que las veces que la marca, producto o mensaje aparece ante el usuario pueden ser ilimitadas, con lo que, al menos el recuerdo de 
marca, podría quedar mucho más garantizado. Por otro lado, siempre que la publicidad no suponga un estorbo para el desarrollo del juego, los jugadores no suelen considerarla como algo molesto, afirman los anteriores autores, a diferencia de otros muchos medios. Entre otras cosas, porque en los casos en los que el juego trata de copiar la realidad, determinados escenarios sin publicidad sí que parecerían extraños, incluso incomodarían. Piénsese, por ejemplo, en un circuito de carreras, donde la presencia de marcas podría incluso agradar, al otorgarle mayor realismo a este y otros escenarios.

Los juegos electrónicos o videojuegos, al margen de los que no son puramente domésticos, pueden ser vehiculados a través de consolas desarrolladas ex profeso para ello, acompañadas de televisores o de manera independiente si incorporan una pantalla. $\mathrm{O}$ bien a través del ordenador, por Internet o no. Y también lo pueden hacer a través del teléfono móvil, lo cual podría ser bautizado como mobile advergaming o $m$-advergaming. Esta industria de los juegos para el móvil, en amplia expansión al igual que la industria de las ya mencionadas apps, supone una gran oportunidad para desarrollar nuevas presencias publicitarias y maneras de comunicar e interactuar con los consumidores. Esto, junto al crecimiento de este tipo de ocio entre los consumidores, en términos tanto de dinero como de tiempo (Kaikati y Kaikati, 2004), hace pronosticar un rápido crecimiento de la inversión en este tipo de publicidad.

Lo audiovisual, por otro lado, se "ludifica", por usar el término de Pérez (2012), esto es, la narrativa audiovisual de muchos formatos, también los publicitarios, adopta con cierta asiduidad características fundamentales del juego. Estamos sin duda, en la era de ese nuevo vocablo, cada vez más presente y con más pujanza, la "gamificación", de mayor éxito que "ludificación", y que vendrá definida por Deterding et al. (2011) como "the use of game design elements in non-game contexts". La comunicación, también la publicitaria, que quiera entrar de lleno en ese proceso de "gamificación", deberá pasar por explotar al máximo las posibilidades audiovisuales de cualquiera de los dispositivos, artefactos y soportes por los que quepa el más mínimo resquicio de comunicación publicitaria en pro de todo tipo de organizaciones, empresas, productos y marcas.

En otro orden de cosas, si bien es verdad que los videojuegos empezaron y siguen siendo algo más propio de los jóvenes, parece que esto está cambiando con cierta celeridad, como ponen de manifiesto casos como la Wii o el Brain Training, donde puede verse cómo sectores menos jóvenes de población se acercan al fenómeno, siendo por ende accesibles también a las estrategias de advergaming. Por tanto, se trataría de una modalidad de comunicación publicitaria, audiovisual y publicitaria, cada vez más pertinente para todo tipo de perfiles de consumidores. 


\subsection{Publicidad audiovisual en los dispositivos móviles}

Hablando de la convergencia entre televisión e Internet, hay quien ya apuntaba hacia otros campos donde una convergencia semejante también se está produciendo, y a un ritmo más acelerado si cabe: la telefonía móvil, "ya que el teléfono se convertirá en televisor, mando a distancia [no sólo del televisor] u ordenador. La convergencia en dispositivos móviles (no sólo la telefonía, sino también los asistentes personales o PDAs, los webpad o los Pocket PC) es imparable." (Pérez de Silva 2000: 96). Más arriba se comentaba que costaba cierto esfuerzo discernir si ante un determinado aparato se estaba ante un televisor con ordenador, o un ordenador con televisor. O una tercera cosa, nueva por completo. Exactamente lo mismo está ocurriendo con los dispositivos móviles. Hoy, ante un determinado producto del mercado se puede dudar de si se está ante un teléfono móvil con agenda electrónica, o de una PDA (Portable Device Assistant) que es casi un portátil, con posibilidad de comunicación telefónica incluso, o un portátil que es teléfono y mucho más, o bien un nuevo híbrido entre los tres conceptos, a lo que habría que sumarle televisor, reproductor de música, y otras prestaciones que se van incorporando día a día.

Pero al margen de este detalle terminológico, que pronto las estrategias comerciales del mercado terminarán por clarificar, ya el mencionado Pérez de Silva (2000) hacía referencia a una revolución global en el plano de la televisión en el móvil. Cierto es, que el desarrollo tecnológico de las posibilidades audiovisuales del móvil no ha ido parejo estos primeros años a una demanda masiva de las mismas, debido principalmente al coste que los terminales con dichas prestaciones tenían hasta hace poco para el usuario. Además, la oferta de contenidos para dichas prestaciones era ínfima en estos primeros momentos. A pesar de ello, lo audiovisual en el móvil es hoy una realidad no ya tan incipiente, perfecta y tecnológicamente preparada para convertirse en un fenómeno masivo, si bien el camino no será otro que el que marque Internet, dejando al margen otras tentativas que durante los inicios del siglo XX se llevaron a cabo, y que quedaron en el camino. Una vez que parece que el móvil ha renunciado, al menos de momento, de transmitir televisión en directo, de contenidos en tiempo real, le sobra con ser un medio de contenidos audiovisuales bajo demanda, disponibles de manera más o menos constante y siendo el usuario el que decide cuándo acceder a ellos.

Repasando la corta historia de la comunicación audiovisual en y para el móvil, en el plano de los contenidos, cabe mencionar casos pioneros en España como el de la serie experimental de 40 capítulos Supervillanos, de Globomedia y Amena, que sirvió para testar producto y mercado, allá por noviembre de 2005 (López García, 2007). Luego vinieron otras de la MTV, 
"Head a Body", o "Meet or delate", que consistió en varios episodios de unos pocos minutos, también llamados píldoras o movisodios. Por la misma fecha, la operadora británica 3 lanzó el primer programa de televisión interactivo para el móvil, "Dubplate Drama", donde la clave era que cada episodio terminaba ante un dilema del protagonista que los usuarios debían resolver, con sus votaciones, de manera que el capítulo siguiente comenzaba según decidían éstos últimos ${ }^{4}$. La serie trataba de un joven que crea un grupo musical y se quiere introducir en el mundo de las discográficas, línea argumental que daba pie, además, para generar un tráfico de descargas de contenidos, como música, vídeos, o diarios, entre otras cosas, generados tanto por la productora como también por los propios usuarios, con lo que se puede observar el rendimiento comercial y publicitario que se pretendía.

Es verdad que también han ido surgiendo iniciativas de creación audiovisual para el móvil independientes a todo interés comercial o mercadotécnico. Es el caso del Global Short Film Project, proyecto de creación cinematográfica puesto en marcha por el Sundance Film Festival y presentado en el congreso de telefonía móvil que tuvo lugar en Barcelona en febrero de 2007. Esta iniciativa demuestra que no sólo para la televisión, sino también para el cine puede el móvil ser otro vehículo idóneo. Pero lo cierto es que la voz cantante la ha llevado, al menos hasta el momento, la industria publicitaria y mercadotécnica. Todo avance de las posibilidades comunicativas del móvil venía de la mano de unos u otros objetivos de marketing. Al principio esos avances suponían una publicidad móvil, una comunicación comercial en general, "preaudiovisual", limitándose a sacarle el máximo rendimiento a las prestaciones que la gran masa de móviles circulantes por los países desarrollados ya poseían. La primera comunicación comercial por móvil es textual, a través de los SMS (Short Message System) o mensajes de texto, ya fueran del anunciante al receptor o de éste al anunciante, sirviéndose para ello de sinergias con otros medios publicitarios, principalmente la televisión. La escasamente exitosa tecnología Bluetooth también permitió el intercambio de estos mensajes textuales, de manera bidireccional, a lo que pronto se le incorporaría la imagen estática, a la par que llegaron las posibilidades fotográficas al móvil. Seguidamente llegaron los MMS o Multimedia Message System, los cuales incorporaron imágenes en movimiento, si bien de manera muy rudimentaria. Esos pasos iniciales de lo que viene llamándose mobile marketing, aunque también podría llamarse perfectamente publicidad móvil, vienen ligados al soporte de otros medios, en especial la televisión e Internet, de tal manera que para el despegue definitivo de esta "cuarta pantalla" como medio audiovisual en general y publicitario en particular, ha sido

\footnotetext{
${ }^{4}$ Este caso de interactividad en el desarrollo argumental no es la primera vez que se ve en una serie de televisión. La serie española Mar de dudas, del productor de TVE Eduardo Esquire, por ejemplo, ya lo puso en marcha en TV, valiéndose del teléfono fijo. Ahora bien, sí constituye "Dubplate Drama" el primer caso a través del móvil, por donde el medio de emisión y de respuesta se unifican (Ortega, 1995).
} 
fundamental ese apoyo en la segunda y tercera pantallas ${ }^{5}$, si bien todo indica que podemos estar cerca de su emancipación.

\section{Conclusiones}

Parece obligado entender, por todo ello, que el futuro de la comunicación publicitaria, resultante de esa hibridación entre Internet, los dispositivos móviles y la comunicación audiovisual, no pasa por entenderla como la unión, sin más, de sonido e imágenes en movimiento en un mensaje acabado que es emitido por unos pocos, a través de cualquier medio con capacidad para ello, y es percibido por otros muchos. A ello habría que añadirle la interactividad y la capacidad de retroalimentación inmediata y continuada por un lado, y por otro, en parte a raíz de lo anterior, la diferenciación de los mensajes de individuo a individuo. Si a todo ello se le añade la capacidad de producción y emisión de mensajes audiovisuales que las nuevas tecnologías ha puesto en manos de la ciudadanía, en especial Internet y el móvil, se podría estar ante un verdadero cambio de paradigma de la comunicación de masas, donde el poder de la comunicación se reparte de manera mucho más equilibrada entre emisor y receptor, donde la frontera entre uno y otro se diluye por completo, hecho del que no quedaría fuera, ni mucho menos, la comunicación publicitaria.

En conclusión, no cabe más que acabar dándole la razón a Pérez de Silva (2000: 81) y decir con él que dentro de esta "tercera revolución industrial" que supone la e-conomía, y sus autopistas de la información, el negocio del siglo XXI es audiovisual: "Ningún experto duda de que el nuevo medio de comunicación resultante de la fusión entre web y televisión, así como la producción y sobre todo distribución del material audiovisual, conforman la gran oportunidad de negocio del siglo XXI." No parece inteligente que la publicidad se mantuviese al margen de todos estos cambios. Al echarle un simple vistazo a su historia, a la relación que siempre ha mantenido con el desarrollo tecnológico y cada una de las nuevas posibilidades comunicativas que éste le ponía al alcance de la mano, se puede estar convencido de que no ignorará tales cambios, antes todo lo contrario. Advertía Maquiavelo que cualquiera que desee un éxito constante debe cambiar su conducta a la par de los tiempos, en lo que luego coincidiría Tomasso di Lampedusa. Con dicha frase del autor renacentista es como empezaba hablando del futuro de la publicidad Jaffe (2005), quien

\footnotetext{
${ }^{5}$ Cuneo (2005), Palmer (2006), o Livingston et al. (2006) entre otros, hablan del móvil como "la tercera pantalla", dejando fuera de su enumeración al cine. Aquí en cambio, se prefiere incorporar a dicho medio dentro del cómputo global de pantallas por las que ha ido transitando y desarrollándose la comunicación audiovisual humana.
} 
avisaba de que para la publicidad (audiovisual) quedaba mucha vida más allá del spot de treinta segundos, cosa que algunos años más tarde podemos corroborar.

\section{Bibliografía}

Anaut, N. (1990). Breve historia de la publicidad. Buenos aires, Claridad.

Bustamante Ramírez, E. (1999): La publicidad en televisión: de los canales tradicionalistas a la televisión digital. En Fernández Areal. Actas de las $V$ Xornadas de Comunicación Social. Pontevedra, Universidad de Vigo.

Chorianopoulos, K. y Lekakos, G. (2008). Introduction to Social TV: Enhancing the Shared Experience with Interactive TV. International Journal of Human-Computer Interaction, 24 (2), 113-120.

Cuneo, A. Z. (2005). Marketers Get Serious about the 'Third Screen. Advertising Age, 76 (28), 6.

Deterding, S., Khaled, R., Nacke, L.E. y Dixon, D. (2011). Gamification: Toward a Definition. CHI 2011 Gamification Workshop Proceedings, Vancouver, BC, Canada.

Gallego Aguilar, A. F. (2011). Diseño de narrativas transmediáticas: guía de referencia para las industrias creativas de países emergentes en el contexto de la cibercultura. Recuperado el 21 de abril de 2013. Disponible en http://www.afoxcp.com/dw/Diseno_narrativas_transmediaticas_Gallego_2011.pdf

García García, F. (2006). Videojuegos y virtualidad narrativa. Icono 14, № 8, 1-24.

García Uceda, M. (1995). Las claves de la publicidad. Madrid, ESIC.

Garrand, T. (2001). Writing for Multimedia and the Web. Boston: Focal Press.

Hernández, M. D., Minor, M. S., Suh, J. Chapa, S. y Salas, J.A. (2005). "Brand Recall in the Advergaming Environment", en Stafford, M. R. y Faber, R. J. (eds.): Advertising, Promotion, and New Media. Nueva York: M. E. Sharpe.

Hewitt, P. G. (2004). Física conceptual. México: Pearson.

Jaffe, J. (2005). Life after the 30-second spot. Energize your brand with a bold mix of alternatives to traditional advertising. Nueva York: Wiley \& Sons.

Jenkins, H. (2003). Transmedia Storytelling. Technology Review (online). Encontrado el 1 de mayo de 2013. Disponible en http://www.technologyreview.com/Biotech/13052/?a=f 
Kaikati, A.M. y Kaikati, J.G. (2004). Stealth Marketing: how to reach consumers surreptitiously, California Management Review, vol. 46, no 4, verano, 6-22.

León, J. L. (1996). Persuasión de masas. Psicología y efectos de las comunicaciones sociopolíticas y comerciales. Bilbao: Deusto.

Livingston, G., Siegel, D. L. y Coffey, T. J. (2006). Marketing to the New Super Consumer Mom \& Kid Nueva York: Paramount Market.

Lochrie, M. y Coulton, P. (2012). Tweeting with the telly on! Mobile Phones as Second Screen for TV. IEEE Consumer Communications and Networking Conference, 729-731.

López García, X. (2007). Informe da Comunicación en Galicia 2007. Santiago de Compostela: Consello da Cultura Galega.

Lowrey, T. M., Shrum, L. J. y McCarty, J. A. (2005). The future of television advertising, en

Kimmel, A. J. (ed.): Marketing Communication: New Approaches, Technologies, And Styles. Nueva York: Oxford University Press.

Martí Parreño, J. (2005). Publicidad y Entretenimiento en la web. Madrid: RA-MA.

Moorey-Denham, S. y Green, A. (2007). "The effectiveness of online video advertising". Admap, marzo, pp. 45-47.

Mu, M., Simpson, S., Bojko, C., Broadbent, M., Brown, J., Mauthe, A., Race, N., Hutchison, D. (2013). Storisphere: from TV watching to community story telling. IEEE $\begin{array}{llll}\text { Communications } \quad \text { Magazine, } & 51 & \text { (8), }\end{array}$ http://dx.doi.org/10.1109/MCOM.2013.6576348.

Negroponte, N. (1995). El mundo digital. Barcelona: Ediciones B.

O'guinn, T. C., Allen, C. T. y Semenik, R. J. (1998). Publicidad. México: Thomson.

Ortega, P. (1995). "TVE emitirá la serie «Mar de dudas» con los finales elegidos por el público". Encontrado en www.elmundo.es/papel/hemeroteca/1995/08/12/ television/59407.html (13/11/2007).

Palmer, S. (2006). Television Disrupted: The Transition from Network to Networked TV. Nueva York: Focal Press.

Pérez De Silva, J. (2000). La televisión ha muerto. La nueva producción audiovisual en la era de Internet, la tercera revolución industrial. Barcelona: Gedisa.

Pérez, O. (2012). El valor del juego. 'Ludificación' en la narrativa audiovisual contemporánea. Telos. Cuadernos de Comunicación e Innovación, 93, 23-33. 
Puig, I. (2005. Pantallas de LEDs. La tecnología que gana adeptos en nuestro país. Vídeo Popular, no 112, abril, 46-48.

Saborit, J. (1988). La imagen publicitaria en televisión. Madrid: Cátedra.

Sanabria Martín, F. (1994). Información audiovisual. Madrid: Bosch.

Selva, D. (2009). El videojuego como herramienta de comunicación publicitaria: una aproximación al concepto de advergaming. Comunicación, no7, Vol.1, 141-166.

Smith, P. R. y Chaffey, D. (2005). eMarketing eXcellence: The Heart of Ebusiness. Oxford: Elsevier.

\section{Forma de citar este artículo en bibliografías}

MUÑIZ VELÁZQUEZ, José Antonio (2013): "En torno a la «audiovisualización» de la comunicación publicitaria", en Revista PANGEA, 4, páginas 245 a 262. Red Académica Iberoamericana de Comunicación. Recuperado el _ de http://revistapangea.org de 2 de: 